\title{
Self-injury in social context: an emerging sociology
}

\author{
Peter Steggals ${ }^{1} \cdot$ Ruth Graham ${ }^{1} \cdot$ Steph Lawler $^{2}$
}

Published online: 6 August 2020

(c) Springer Nature Limited 2020

What is being carved in human flesh is an image of society - Mary Douglas Purity and Danger (1966, p. 116)

The last ten years have seen a remarkable increase in sociological interest in nonsuicidal self-injury (more commonly known as self-harm), ${ }^{1}$ which is to say acts, normally repeated and habitual, that in some way cause 'direct harm to the body, but... where the focus and purpose of the[se] act[s] is this harm itself and not some other goal such as decorative body modification or suicide' (Steggals 2015, p. 9). Taking sociology research monographs as a rough indicator: the decade started with the very first to be published that was exclusively dedicated to self-injury, ${ }^{2}$ Patricia and Peter Adler's The Tender Cut (2011). This was followed a year later by Theresa McShane's Blades, Blood and Bandages (2012) and then by Peter Steggals' Making Sense of Self-Harm (2015), Amy Chandler's Self-Injury, Society and Medicine (2016), Elizabeth McDermott and Katrina Roen's Queer Youth, Suicide and SelfHarm (2016), and finally Baptiste Brossard's Why Do We Hurt Ourselves? (2018). Over the same period, Kay Inckle followed up her 2007 book on self-mutilation and body modification, Writing on the Body?, with two books that take a sociologically informed perspective on self-injury: Flesh Wounds? (2010) and Safe With SelfInjury (2017). And alongside these titles we might also mention the works of social and medical history, like Chris Millard's A History of Self-Harm in Britain (2013) and Sarah Chaney's Psyche on the Skin (2017).

There are several good reasons for this increased interest, not least of which is the fact that self-injury is a serious topic representing a significant public health

\footnotetext{
${ }^{1}$ While self-injury is often referred to as self-harm in public discourse, the term has a more general meaning in medical discourse, referring to (following the National Institute of Health and Care Excellence) 'acts of intentional self-poisoning or self-injury irrespective of type of motivation' (2011, p. 5). The medical definition of self-harm then includes but is not limited to non-suicidal self-injury.

${ }^{2}$ Liz Frost's important monograph Young Women and the Body was published in 2001, but dealt with eating disorders as well as self-injury.
}

Peter Steggals

Peter.Steggals@newcastle.ac.uk

1 Newcastle University, Newcastle upon Tyne, UK

2 Department of Sociology, University of York, Wentworth College, York, UK 
issue. For example, a recent repeated cross-sectional study found that the prevalence of self-injury has risen steeply in England, with lifetime prevalence rates increasing from 2.4\% of the population in 2000 to $6.4 \%$ in 2014 (McManus et al. 2019). Meanwhile, analysis of English primary care data showed that, between 2011 and 2014, the incidence of the broader medical category of 'self-harm' (which includes, but is not limited to, self-injury) increased by 68\% in girls aged 13-16 (Morgan et al. 2017). It has long been acknowledged that the UK has a particular problem with self-injury, ${ }^{3}$ an issue publicly highlighted in recent years for example by the questions and dilemmas that followed Molly Russell's death and the subsequent Instagram ban on images of self-injury. ${ }^{4}$ But the issue is also of international significance, as indicated by its inclusion in the 5th edition of the Diagnostic and Statistical Manual of Mental Disorders (2013, p. 803) as a self-contained category of disorder, rather than as a symptom attached to other disorders.

But alongside this considerable practical importance, self-injury is also an object of intense theoretical significance. Indeed, in one sense it represents a contemporary version of what suicide represented for Emile Durkheim in the nineteenth century (2002 [1897]). On the one hand, it appears to be the perfect example of a purely individual, private and self-evidently psychological practice: a disruption of the inner life, not the social life; a pathology of private thoughts and feelings, not of relationships and interactions. But on the other hand, and for this very reason, selfinjury also represents an important case study in how deeply sociocultural factors reach into the personal life of everyday subjectivity. From this point of view, one which is supported in different ways by the articles in this special issue, there can be no sharp or absolute distinction between the inner and the outer, the personal and the social. Self-injury then must be explored and analysed as much along its sociological dimension as its psychological dimension. Indeed, as Millard (2013) has demonstrated, the sense in which self-injury is something that is self-evidently psychological is more the product of a social history than it is the reflection of a natural fact. Prior to the 1980s, self-injury was largely understood as 'a response to, or communication with, a social circle or another person' (Millard 2013, p. 2). But alongside the increasingly acute individualism of late-modernity, self-injury was effectively reframed as a 'largely non-communicative' mechanism of the individual psyche 'designed to regulate internal emotional states' (ibid). Today, this highly individualist understanding is dominant; it is not uncommon to see communicated self-injury questioned and even dismissed as 'inauthentic' and 'attention-seeking' (Chandler 2016; Scourfield et al. 2011; Steggals et al. 2020a, b).

However, despite the contemporary dominance of this non-social framing, a large body of research, including but not limited to the sociological work listed above, is beginning to demonstrate that much self-injury contains an important relational,

\footnotetext{
${ }^{3}$ For example, see https://www.nursinginpractice.com/article/manchester-worst-self-harm accessed 11 June 2020.

${ }^{4}$ See https://www.bbc.com/news/technology-50129402; for some discussion of these issues see https ://www.thesociologicalreview.com/seeing-self-harm-as-an-embodied-social-practice/ and https://www. thesociologicalreview.com/can-we-look-at-self-harm/ all accessed 11 June 2020.
} 
communicative and even interactional dimension (Brown et al. 2002; Nock. 2008; Nock and Prinstein 2004, 2005; Rodham et al. 2004; Steggals et al. 2020a, b; Turner et al. 2012). In addition, studies have also demonstrated that self-injury is intrinsically tied into its immediate social setting (Brossard 2018; Brossard and Steggals 2020; Chandler 2016, Chandler et al. 2020; Cresswell 2020; McDermott and Roan 2016; McShane 2012, 2020), is responsive to its discursive construal (Adler and Adler 2011; Chaney 2017; Cresswell 2020; Millard 2013), and may well reflect or even articulate the sociocultural and political forces at work in the broader social context (Frost 2001; Inckle 2020; Steggals 2015).

This special issue results from a symposium that we (Steggals, Graham and Lawler) organised and held in April 2018, The Social Life of Self-Harm. This symposium, funded by the Foundation for the Sociology of Health and Illness and the Student Health and Wellbeing Service at Newcastle University, UK, grew out of our recognition of the increased sociological interest in self-injury and the emergence of a distinct sociology of self-injury literature. The symposium gathered together some of the principal sociologists and historians involved in these developments and represented a unique opportunity to share and consolidate research findings, reflect upon the field as a whole, and collectively discuss how it needs to develop in order to deliver the highest possible benefits both to our understanding of self-injury and to the sociology of health and illness. The presentations on the day, and the papers collected here, highlight the importance of how we theoretically frame practices like self-injury: how we bring certain aspects of them into view by taking a particular perspective, but in so doing allow other aspects to disappear into the background. As the individualist framing of much of the medical and psychological literature has brought the biological and intrapsychic life of the individual who self-injures into view, it has done so at the cost of de-emphasising, or even concealing, the social, communicative and political condition and context of that same life. The papers gathered together in this special issue help us to address this problem by altering our theoretical and methodological frame. By taking a different perspective we can bring these all-too-often de-emphasised or covered over aspects of self-injury back into view, while at the same time endeavouring to keep the bio-psychological life of the individual person fully in mind. The phenomenological concept of adumbration is potentially useful here, in illustrating what we have in mind: with successive, differing points of view (or adumbrations) of an object standing less as competing accounts of it, than as components of a complex yet unified apprehension.

Our special issue begins with contributions from Baptiste Brossard and Kay Inckle who each mount a challenge to the medicalised framing of self-injury, and, in different ways, draw attention to the kind of self this framing implies. Indeed, our conceptualisation of the nature and limits of the self is one of the things that is brought decisively into view in presentations and understandings of, and responses to, self-injury. The almost-automatic diagnosis of Borderline Personality Disorder (also known as Emotionally Unstable Personality Disorder) that was until recently a common experience of people presenting with self-injury is one, clinical, manifestation of this (where the personality, cast as the source of the self, is framed as faulty). So too are the presentations of self of those who self-injure, as they develop 
an awareness of the body that is marked with the stigmatic signs of injury; a body then that must be managed (Goffman 1968).

In conversation with Peter Steggals, Baptiste Brossard discusses his research in France and Canada, published as Why Do We hurt Ourselves? Understanding Selfharm in Social Life (2018). Specifically, they discuss Brossard's distinctive framing of self-injury as both a practice of self-control (intended to preserve the Interaction Order) and as a technique used to manage the pressure exerted by the individual's social environment. In this way, corporeal injuries could be cast as responses to the more 'hidden injuries' inflicted on those suffering from social inequalities. But while for Brossard, this self-injurious response is not straightforwardly communicative, it is nevertheless a practice through which people orient themselves - a form of self-understanding and self-narration. As such, self-injury is better framed as a reflexive response to the world than as a manifestation of illness. Furthermore, Brossard draws attention to the ways in which the person's relationship to themselves (including their own body) and to those around them is significant in both practices and understandings of self-injury. This important attention to the webs of relationships within which the person is enmeshed takes us further away from individualistic models. Brossard's highlighting of unconscious fantasy-in which, for example, the body becomes a 'problematic space' and parents may come to stand as fantasised embodiments of social norms - is also significant in moving us towards ways of understanding that do not rely on a means-end rationality, or the 'black box' approach of personality disorders, or a simplistic model of parental failure. The person who self-injures is framed here as an active participant in the Interaction Order, and maker of their own narrative, albeit one working out the constraints of injurious social relations.

Kay Inckle, similarly, frames those who self-injure in active terms, and in terms of their own expertise in ways of managing physical and emotional pains. Drawing on her in-depth research with people with experience of self-injury (whether from their own experience or as service providers) Inckle argues that (unequal) social relations work to compound the harm they cause by casting responses to socially produced harms as matters of individual psychopathology. Noting an increase in these forms of individualisation, Inckle situates this move in the broader context of neo-liberal social relations, in which the person is understood in individual, rather than collective, terms. Against this backdrop, Inckle calls for a social justice perspective, arguing for the need to take account of the social context of structural inequality that individuals cannot help but respond to. Certainly, self-injury is not the only available response, but it is an idiom that may represent a coherent response to intolerable social harm. The key point is that we need to politicise, rather than personalise, this kind of pathogenic distress.

Inckle further suggests that those who practise self-injury may themselves be in the best position to formulate 'what works' in reducing possible harms. In this context, her appeal is to grounded, collective and mutual forms of aid which challenge biomedical models of coping. While medicalisation tends to individualise social problems, and, in the process, exacerbates them, in contrast, user-led techniques rely on a collectivity of users, working with the expertise of personal experience. While conventionally, treatment has focused on prevention, Inckle's work shows how 
practices of harm reduction may produce a more liveable set of outcomes. Indeed, strategies of harm reduction have now entered the mainstream and form part of medical practice and NICE guidelines. This points to questions about the willingness of mainstream institutions to engage with user-led initiatives (see also Cresswell 2020) and raises questions about how service providers can best engage with their users.

The contributions from Amy Chandler et al. and from Mark Cresswell approach the phenomena of self-injury, and the broader medical category self-harm, in the context of the clinic, engaging with the interplay between formal health care provision and broader social responses to social deviance. Their analyses are substantively different, yet theoretically complementary, with both making good use of Jeffrey's (1979) binary concept of the good patient/bad patient. Taken together they demonstrate the complexity of the interrelationships between identities, moral classifications and institutional responses to self-injury.

Amy Chandler, Caroline King, Christopher D. Burton and Steve Platt's article reports on a qualitative study of General Practitioners working in two areas in Scotland, taking self-injury as a case study through which they examine how GPs approach patients with symptoms that are not clearly biomedical. Central to this analysis is the importance of understanding the way in which GPs seek to make sense of self-injury, the ways in which this interpretive activity affects the Doctor-Patient relationship, and consequently, the impact that it can have on treatment decisions, patient outcomes and understandings of self-injury more generally. Drawing on data that provide insights into how GPs tell the 'stories' of their patients who self-injure - and therefore how they conceptualise these patients- the analysis sets out a threefold typology. The 'good girl' category portrays the (usually younger) patient who self-injures as a riddle for GPs to 'solve'. The 'problem patient' category tends to be used in relation to older patients with a longer history of self-injury, where GPs tend to articulate their role as a frustrating one. The final category of 'out of the blue' patients throws into sharp relief the way in which GPs draw on broader gendered cultural narratives about self-injury to help make sense of individual cases. While the other two categories consisted mostly of female patients, the 'out of the blue' category was associated only with male patients, and was made up of those who were seen as exhibiting more 'serious' issues, and whose self-injury was interpreted through the more inclusive category self-harm as attempted suicide. Chandler et al.'s analysis, then, helps to unpack the way in which social relationships, identities and cultural meanings all help to contextualise and shape the way GPs come to understand their patients, and sets out the impact that these understandings can have on the Doctor-Patient relationship.

In contrast, Cresswell's article uses moral code theory, in particular Alexander's (2006) version, as a way to analyse the social reaction to, and treatment of, non-fatal self-harm in accident and emergency departments in the NHS in England. By examining two contemporary areas of health and social policy - the NICE guidelines on self-injury (specifically clinical guideline 16) and the Mental Health Act, 1983 (specifically section 136) - this analysis demonstrates that self-harm is typically framed with reference to three forms of moral classification, as a mental health problem; an issue of immorality; and/or an issue of criminality. The influence of these different classifications has shifted over time (so for example, self-harm was framed less in 
terms of criminality after its decriminalisation in the 1961 Suicide Act, but is now being framed in this way again due to the role of detention under section 136) but they nonetheless exist in an ongoing, complex and dynamic relationship. Cresswell notes that how a particular person's self-harm is understood (as primarily a matter of mental health, or immorality, or criminality) helps frame them, in the social context of the accident and emergency department, as being either a 'good patient' whose self-harm is the result of illness, or as a 'bad patient' whose self-harm is the result of immoral or criminal tendencies. The complexity of how this binary of the good/ bad patient operates is brought out in relation to multiple facets of socially informed understandings. For example, the articulation of the good/bad binary has changed over time, whether one considers the changes brought about by the legal framework for self-harm, or the role of recurrent self-harm behaviours for an individual, whereby older patients with a more extensive history of self-harm presentation are more likely to be categorised in more negative terms. Similarly, classifications of self-harm differ relative to the complexities of dual diagnosis, with some mental health conditions being conceptualised as more benign than others in relation to the goal of preventing harm-either to the self, or to others. By providing such a complex and nuanced analysis, Cresswell's contribution extends our sociological understandings of how moral categories are infused into the structure and responses of the social institutions in which self-harm is engaged.

While the contributions from Chandler et al. and Cresswell are distinct, they also express some important common themes: both draw significant insight from the conceptualisation of patients in moral terms. Indeed, both draw on Jeffrey's (1979) work, that in turn draws on the concept of the sick role (Parsons 1951) and the part it plays in legitimising a lack of social functionality. This theoretical background stands as a conceptual cornerstone in both articles such that, together, they help us to understand the ways in which social deviance perspectives can be further developed in relation to self-injury and self-harm. Furthermore, both contributions demonstrate the complex ways in which moral evaluations and judgements of moral culpability have a substantive impact on how patients are understood, and how care options are influenced by social and cultural meanings.

Finally, our own contribution and that of Theresa McShane remind us that if we are to examine self-injury in social terms then we must take seriously not only the individual who self-injures and the medical professionals who diagnose and treat them, but also the whole network of social relations and interactions that surrounds and pervades the life of someone who self-injures. Both articles bring into view the perspectives of other people who belong or otherwise appear in these networks, and who must find a way to approach and understand self-injury, often without personal experience or medical training.

Our article draws on an English pilot study about self-injury and social relations, and specifically examines parents' experiences of living and interacting with children who self-injure, using a phenomenologically informed analysis to explore some of the communicative processes, spaces and impacts associated with these experiences. Taking as our starting point the growing recognition of a communicative dimension to self-injury, we argue that regardless of whether or not selfinjury is modelled within the terms of deliberate interpersonal communication, it is 
undeniably something that has a significant impact on the social and communicative fields that exist between people. And as such, it is something that can be explored and understood as communicative in this more general sense.

By reorienting our perspective to attend to this more general sense of communication, we are able to re-view the interpersonal while also bringing the intersubjective and the intercorporeal into focus. Through these three levels of observation we explore the rich, if characteristically ambiguous social life of self-injury. However, this reorientation implies a shift in theoretical perspective as well as methodological attention. In order to understand this communicative activity, we argue that we must move beyond our attachment to the traditionally dominant sender-receiver paradigm of communication as well as the closely related concept of the individual as bounded and monadic, or what Elias famously calls the homo clausus (Elias 2000 [1939]). In place of the former, we must turn to newer, multimodal approaches to communication. And in place of the latter, the tired dichotomies of the inside/outside and the private/public need to be replaced with a more fluid model of the always already intersubjective: less a closed body then, than a 'communicative body' (Frank 1991; O’Neill 1989).

In her contribution, Theresa McShane also considers how self-injury is approached and understood by others outside of the groups more commonly surveyed: i.e. those who self-injure and those who represent medical expertise on selfinjury. But this time, rather than parents, it is the question of how social researchers should approach self-injury as a topic of enquiry that is before us. Her article is a narrative reflection on some of the issues and challenges that she faced in her qualitative research with people who self-injure, subsequently published as the monograph, Blades, Blood and Bandages (2012). As a general principle, McShane emphasises the need to take people's own accounts as authoritative in forming an understanding of their actions, but adds that when a practice is as sensitive and stigmatised as self-injury, the primary challenge is facilitating the right environment in which this account can be given. In particular, she focuses on her experiences of recruiting participants, what motivated people to participate in her research, conducting interviews, and managing the more difficult or potentially negative effects that such research experiences can have on both participant and researcher. McShane's reflections certainly help us to think through some of the more practical and overlooked challenges in constructing methodologies for researching sensitive topics from a first-person perspective. But her primary lesson for social researchers is to work on breaking down some of the power differentials implicit in the researcher-participant relationship, and to do so by approaching people as the principal authority on their own behaviour. This approach, as McShane points out, should be as open, collaborative and jargon-free as possible. Indeed, this is an ethos she believes should pervade the entire research process.

Just as the sociological perspective on self-injury can be added to those already developed in psychotherapy, clinical psychology and psychiatry, so too there are multiple perspectives of focus and methodology available within sociology. The articles collected here clearly demonstrate this, not only in the diversity of their approaches but also in the variety of relationships and interactions that they focus on. However, this diversity does not mean that there are no overarching themes that 
emerge between the articles and that are close to the core interests of sociology as a discipline. For example, one such theme is that all of the different kinds of relationships explored here-social authority/subject (Inckle), medical professional/patient (Inckle, Chandler et al. and Cresswell), peer-to-peer and parental/child (Brossard and Steggals, and Steggals et al.), and researcher/participant (McShane)—imply the presence and activity of moral evaluations and judgements of moral culpability. While the articles by Brossard and Steggals, Inckle, and Steggals et al. draw out this dimension of moral evaluation and judgement as a common feature of social life and its processes, the articles by Chandler et al. and Cresswell very clearly show how this dimension specifically affects the sense making activity of clinicians, while the article by McShane suggests that the implicit presence of such evaluations and judgements can be obstacles to the researcher/participant relationship and so must be honestly faced and carefully managed. And as a common theme that runs through all of the articles collected here, this dimension of moral evaluations and judgements helps us to envisage what this emerging sociology of self-injury has to offer existing bodies of knowledge. Namely, that the personal experience and life of the individual who self-injures can only be fully understood if they are understood within their social context: that is, understood as something fundamentally embedded within a web of relationships and interactions. But, by the same token, if we are called on to appreciate that the personal always already involves the social, then we must also pay attention to the multiple ways in which the social focuses effects on, and is articulated through, the personal feelings, experiences, and indeed bodies of living individuals. Self-injury represents a powerful case study in precisely this way. It is a living example of how the personal and the social ought not be thought of as two separate weights to be balanced out in the scales of a comprehensive theory, but rather represent methodological refractions drawn out from a single, complex and simply human reality.

Acknowledgements We are grateful to the Foundation for the Sociology of Health and Illness and the Student Health and Wellbeing Services at Newcastle University, UK, for their support and generosity in funding the symposium from which this special issue has been developed. We would also like to thank all those who contributed papers for that day: Theresa McShane, Chris Millard, Mark Cresswell, Amy Chandler, Baptiste Brossard and Kay Inckle. Of course, a symposium is impossible without contributors, but it is equally impossible without all the people who attend and contribute their time and attention as well as their questions and ideas, so a big thank you must also be given to all our attendees who came from an impressive range of backgrounds to participate in that day's shared conversation. Our appreciation is also extended to the referees who reviewed the papers collected in this special issue and whose comments have proven invaluable. We would like to thank the journal, Social Theory and Health, for their generosity and support, especially Rebecca Scambler for her impressive reserves of patience and expertise. And finally, we would like to thank our wonderful contributors for the time and energy they have invested in this special issue, and the support they have shown to its editors.

\section{References}

Adler, P., and P. Adler. 2011. The tender cut: Inside the hidden world of self-injury. New York: New York University Press.

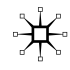


Alexander, J. 2006. The meanings of social life: A cultural sociology. Oxford: Oxford University Press.

American Psychiatric Association. 2013. Diagnostic and statistical manual of mental disorders, 5th ed. Washington, DC: American Psychiatric Association.

Brossard, B. 2018. Why do we hurt ourselves? Understanding self-harm in social life. Bloomington: University of Indiana Press.

Brossard, B., and P. Steggals. 2020. The sociological implications of taking self-Injury as a practice: An author meets critic interview. Social Theory \& Health. https://doi.org/10.1057/s41285-020-00131-3.

Brown, M.Z., K.A. Comtois, and M.M. Linehan. 2002. Reasons for suicide attempts and nonsuicidal selfinjury in women with borderline personality disorder. The American Journal of Psychiatry. 152: 1788-1793.

Chandler, A. 2016. Self-injury, medicine and society: Authentic bodies. Basingstoke: Palgrave Macmillan.

Chandler, A., C. King, C.D. Burton, and S. Platt. 2020. The social life of self-harm in general practice. Social Theory \& Health. https://doi.org/10.1057/s41285-020-00139-9.

Chaney, S. 2017. Psyche on the Skin: a History of Self-Harm. London: Reaktion Books.

Cresswell, M. 2020. Self-harm and moral codes in emergency departments in England. Social Theory \& Health. https://doi.org/10.1057/s41285-020-00137-x.

Douglas, M. 1966. Purity and Danger: An analysis of concepts of pollution and taboo. London: Routledge \& Kegan Paul.

Durkheim, E. 2002 [1897]. Suicide: a study in sociology. Oxon: Routledge

Elias, N. 1994 [1939]. The Civilizing Process (Jephcott E., trans.). Oxford: Blackwell.

Frank, A. 1991. For a sociology of the body: An analytical review. In The body: Social process and cultural theory, ed. M. Featherstone, M. Hepworth, and B.S. Turner. London: Sage.

Frost, L. 2001. Young women and the body: A feminist sociology. Basingstoke: Palgrave.

Goffman, E. 1968. Stigma: Notes on the management of spoiled identity. New York: Simon and Schuster.

Inckle, K. 2007. Writing on the body? Cambridge: Cambridge Scholars Publishing.

Inckle, K. 2010. Flesh wounds? New ways of understanding self-injury. Herefordshire: PCCS Books.

Inckle, K. 2017. Safe with self-injury: A practical guide to understanding, responding and harm-reduction. Herefordshire: PCCS Books.

Inckle, K. 2020. Inequality, distress and harm-reduction: A social justice approach to self-injury. Social Theory \& Health. https://doi.org/10.1057/s41285-020-00146-w.

Jeffery, R. 1979. Normal rubbish: Deviant patients in casualty departments. Sociology of Health and Illness 1 (1): 90-108.

McDermott, E., and K. Roen. 2016. Queer youth, suicide and self-harm: Troubled subjects, troubling norms. Basingstoke: Palgrave Macmillan.

McManus, S., D. Gunnell, C. Cooper, P.E. Bebbington, L.M. Howard, T. Brugha, R. Jenkins, A. Hassiotis, S. Weich, and L. Appleby. 2019. Prevalence of non-suicidal self-harm and service contact in England, 2000-14: Repeated cross-sectional surveys of the general population. The Lancet: Psychiatry 6 (7): 573-581.

McShane, T. 2012. Blades, blood and bandages: The experiences of people who self-injure. Basingstoke: Palgrave Macmillan.

McShane, T. 2020. You want to know why I cut? Reflections on doing research with people who selfinjure. Social Theory \& Health. https://doi.org/10.1057/s41285-020-00132-2.

Millard, C. 2013. A history of self-harm in Britain: A genealogy of cutting and overdosing. London: Palgrave Macmillan.

Morgan, C., R.T. Webb, M.J. Carr, E. Kontopantelis, J. Green, C.A. Chew-Graham, N. Kapur, and D.M. Ashcroft. 2017. Incidence, clinical management, and mortality risk following self harm among children and adolescents: Cohort study in primary care. British Medical Journal BMJ 2017 (359): j4351.

National Institute for Health and Care Excellence. 2011. Self-harm in over 8s: Long-term management. Manchester: NICE.

Nock, M.K. 2008. Actions speak louder than words: an elaborated theoretical model of the social functions of self-injury and other harmful behaviours. Applied and Preventive Psychology. 12: 159-168.

Nock, M.K., and M.J. Prinstein. 2004. A functional approach to the assessment of self-mutilative behaviour. Journal of Consulting and Clinical Psychology. 72: 885-890.

Nock, M.K., and M.J. Prinstein. 2005. Contextual features and behavioural functions of self-mutilation among adolescents. Journal of Abnormal Psychology. 114: 140-146.

O'Neill, J. 1989. The Communicative Body: Studies in communicative philosophy, politics, and sociology. Evanston, IL: Northwestern University Press. 
Parsons, T. 1951. The social system. London: Routledge \& Kegan Paul.

Rodham, K., K. Hawton, and E. Evans. 2004. Reasons for deliberate self-harm: Comparison of self-poisoners and self-cutters in a community sample of adolescents. Journal of the American Academy of Child and Adolescent Psychiatry 43: 80-87.

Scourfield, J., K. Roen, and E. McDermott. 2011. The non-display of authentic distress: Public-private dualism in young people's discursive construction of self-harm. Sociology of Health \& Illness 33 (5): 777-791.

Steggals, P. 2015. Making sense of self-harm: The cultural meaning and social context of nonsuicidal self-injury. Basingstoke: Palgrave.

Steggals, P., S. Lawler, and R. Graham. 2020a. The social life of self-injury: Exploring the communicative dimension of a very personal practice. Sociology of Health \& Illness 42 (1): 157-170.

Steggals, P., S. Lawler, and R. Graham. 2020b. 'I couldn't say the words': Communicative bodies and spaces in parents' encounters with nonsuicidal self-injury. Social Theory \& Health. https://doi. org/10.1057/s41285-020-00144-y.

Turner, B., A. Chapman, and B. Layden. 2012. Intrapersonal and interpersonal functions of nonsuicidal self-injury: Associations with emotional and social functioning. Suicide and Life-Threatening Behaviour. 42 (1): 36-55.

Publisher's Note Springer Nature remains neutral with regard to jurisdictional claims in published maps and institutional affiliations. 